\title{
Evaluating Human Work in the Digital Factory - A New German Guideline -
}

\author{
Gert Zülch \\ Karlsruhe Institute of Technology, ifab-Institute of Human and Industrial Engineering, \\ Kaiserstrasse 12, D-76131 Karlsruhe, Germany \\ gert.zuelch@gefora-beratung.de
}

\begin{abstract}
Over a period of several years a Guideline Committee of the Association of German Engineers (VDI) engaged in the development of a part of a guideline for computer-aided modelling and ergonomic evaluation of working people in digital factory tools. The subject of this part is to document the state of the art in analysis, evaluation and assessment of stresses and strains through work tasks. Broken down according to the separate aspects of engineering mechanics, it looks at existing anthropometric and physiological functionalities of evaluating human labour, with a distinction made between those that are already required as standard and those that are still considered to be optional and are only applied in a few procedures. It appears that the evaluation methods used often lead to different assessments, and that some necessary functions are not yet realized. Further progress is therefore required from an ergonomic perspective.
\end{abstract}

Keywords: Human models, ergonomics, workplace design, physical stress, evaluation.

\section{VDI Guidelines for Representing Humans in the Digital Factory}

The digital factory already has a proven way of securing the planning of parts manufacturing and assembly systems. In 2008, the Technical Committee "Digital Factory" within the Association of German Engineers (VDI) started with the publication of a series of guidelines for digital factory planning. The first part of this guideline series, VDI Guideline 4499 Part 1 [1], looks at the basics of digital factory planning. The other parts of this guideline series, each of which is developed by a separate Guideline Committee, involved special tools, such as the digital factory operation.

Currently a VDI Guideline Committee is dealing with the ergonomic analysis, evaluation and assessment of stresses and strains of working people through work tasks with tools of the digital factory. Digital human models were first developed in the mid-1980s as progress was made with the processing of graphical data. Today, digital human models are one of the fundamental tools used in connection with the digital factory. But the graphical representations and the available ergonomic evaluations differ substantially from each other in some cases. After more than 25 years of

B. Grabot et al. (Eds.): APMS 2014, Part III, IFIP AICT 440, pp. 35-42, 2014.

(C) IFIP International Federation for Information Processing 2014 
developing digital human models, the question we now face is which human models come into consideration for certain ergonomic aspects, and what limitations the procedures still have.

Figure 1 shows an exemplary virtual representation of a manual assembly system. The new guideline part focuses on the methods available in Germany. Stresses and strains caused by the working environment will be the subject of a future part of the guideline. The current Guideline Committee is composed of representatives from science and software companies as well as industrial users. The draft VDI Guideline 4499 Part 4 [3] was published in 2012. After processing of objections, the final version will appear along with an English translation in mid-2014.

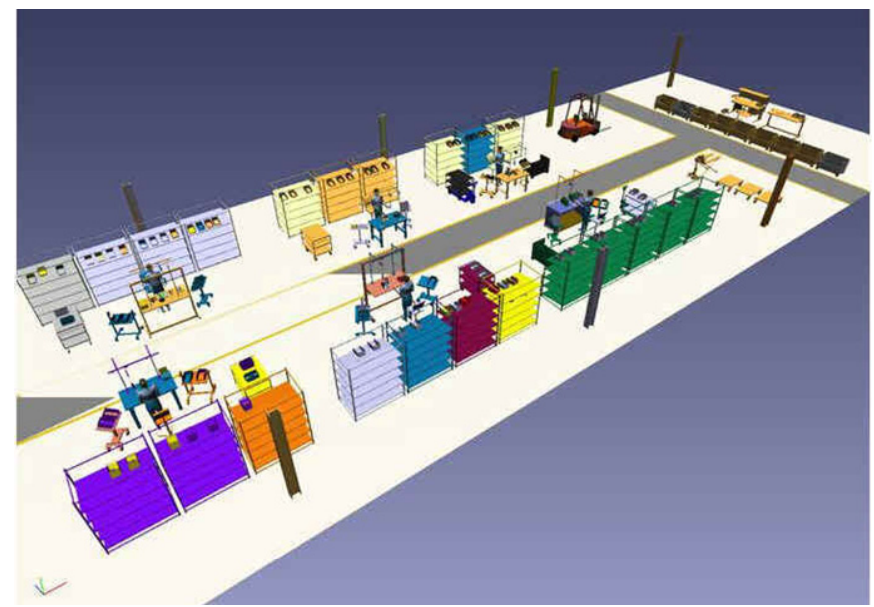

Fig. 1. Visualization of an assembly system [Software: 2]

The new guideline part is different to VDI Guideline 3633 Part 6 [4], already published in 2001, in that it deals with the "Representation of human resources in simulation models". This guideline part is based on a longer-term perspective of human resources from one shift up to many months. In contrast, the focus of the new VDI Guideline 4499 Part 4 is on the dynamic analysis of operations in the second and minute range, and on the evaluation of static working situations.

\section{Functionalities of Ergonomic Human Models}

The structure of the Guideline 4499 Part 4 is based on the different aspects of engineering mechanics, namely geometry, kinematics, statics and dynamics. While from an ergonomic perspective the first two aspects are part of anthropometric design, the latter two constitute physiological work design. For each of these aspects, underlying functionalities are listed that an ergonomic human model should include as well as those that are optional but are present in at least one of the tools available in Germany. The following gives an overview of the characteristic options for modelling and ergonomic evaluation and assessment. 


\subsection{Geometric Analysis}

The geometry of the work system first and foremost concerns the spatial layout of the workplace with furnishings, as well as the geometry of work objects, workpiece carriers and equipment. Here it is apparent that much of the data used in CAD models has no relevance for ergonomic issues, for example tolerances and contact areas between the internal parts of a pre-assembled workpiece.

The second aspect concerns the dimensions of the human body. The statistical percentage values from existing standards and data collections suffice for this purpose, although these usually relate to an unclothed human body. There is much less standardized data on the appropriate clothing, particularly in the case of protective clothing, which represents a problem when examining a person's freedom of movement.

Another problem is the variability of the human body depending on posture. There are only standards relating to the hip or seat width of the human body. It is highly likely that the recently concluded series of studies conducted as part of the SizeGermany project [5] will provide a new set of underlying data. Although these studies are aimed at the clothing industry, they will certainly influence the standardization of body dimensions in other fields.

\subsection{Kinematic Analysis}

Kinematic analysis and evaluation relates on the one hand to the zones of movement of human limbs and also to the time required to carry out these movements. The joints of the human body and the way the limbs move present a particular problem. This is because of the range of relative movements between the surfaces of the limbs and sliding elements, as well as the relationships between the limbs involved in a movement. One example of this is the way in which the shoulder follows when working with your hands above your head. Assuming inflexible limbs and hinge or pointshaped joints, these movements can be approximated using engineering kinematics. These technical conveniences result in a certain degree of inaccuracy in the movement paths and reaching distances when compared with real body movements.

Movement paths can be calculated using forward or inverse kinematics. There are a number of ways to calculate a movement path from a starting point to a destination, for example by applying the principle of minimizing joint excursion based on having the joints at a comfortable angle. But in many cases it is not yet clear which way is the most appropriate one.

Another problem is the speed at which the body motions are carried out. The current state of the art is that the necessary time evaluation is carried out on the basis of predetermined time systems or standard times. Figure 2 visualizes a manual operation together with the Gantt chart representation of the operation sequence and a time evaluation by means of MTM-UAS.

However, the time evaluation by means of a system of predetermined times can only serve as an approximation, for example if movement paths encounter obstacles and loads have to be transported. It is known that the load on the muscles (and therefore also the time required to complete the movement) depends not only on the 
horizontal reaching distance but also on the angle as well as the starting distance and destination distance from the body. Adding the vertical excursion of the hand/arm system as a third dimension further modifies the amount of time required as we would expect.

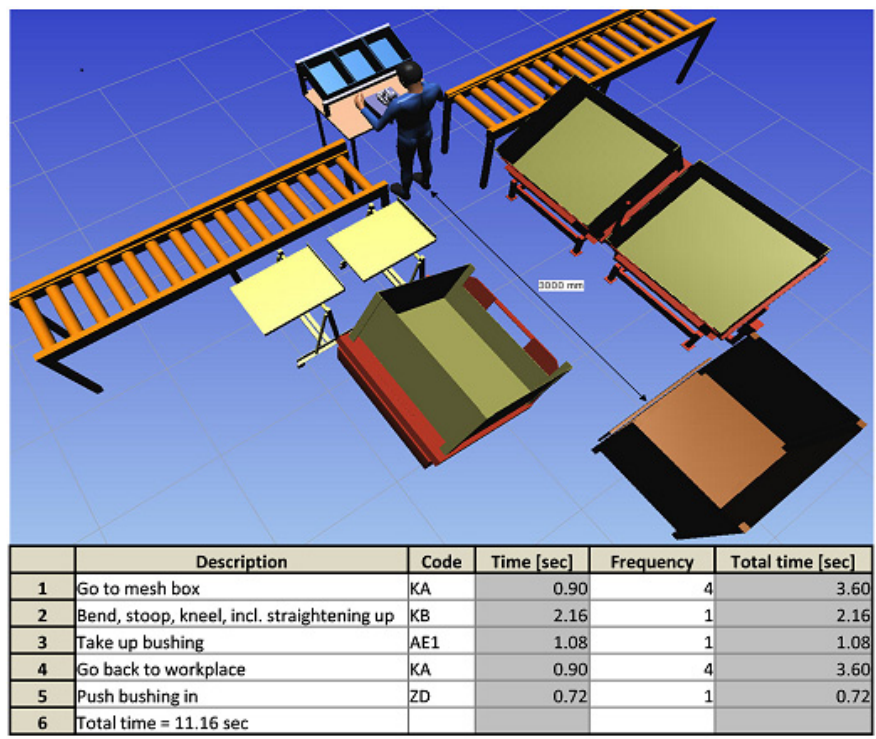

Fig. 2. Workplace layout and time evaluation with MTM-UAS [3, p. 18, transl; Software: 2]

The paths followed by the various parts of the human body and the time required to perform these movements are usually measured by means of motographic recording using real test subjects. However, applying this to human modelling processes requires synthesizing algorithms that allow the parameterized calculation of movement paths and their time requirements. Biomechanical approaches from some research laboratories aimed at developing humanoid robots and in the field of sports science show how this can be done.

\subsection{Static Analysis}

From a static perspective, the movements of the human body are subject to internal and external forces and torques. Therefore, a distinction is made between posture when working (static work posture) and isometric holding work, i.e. of a weight. It may be necessary to further specify the static work down to hand, finger, leg and foot forces and the corresponding torques.

One particular problem is presented by postures that are imposed by the physical dimensions of the work situation. This is especially the case if parts of the body are resting on parts of the work system. Although it is possible in principle to calculate the state of equilibrium for the imposed posture, but this is not done in existing procedures. Instead, posture is represented as a drawing taking into account the geometric 
properties of the human body. Furthermore, this does not take into account the deformation of the body's surface.

There are a number of methods for analysing, evaluating and assessing human static posture and holding work based on kinematic assumptions or even practical approaches. They include the OWAS method (Figure 3) developed in Finland as well as the Guidance Characteristic Method that is widely used in Germany. Interactive calculation forms for the latter method are available on the internet. It also takes into account the time required for a particular static posture or holding task in the form of frequencies per shift.

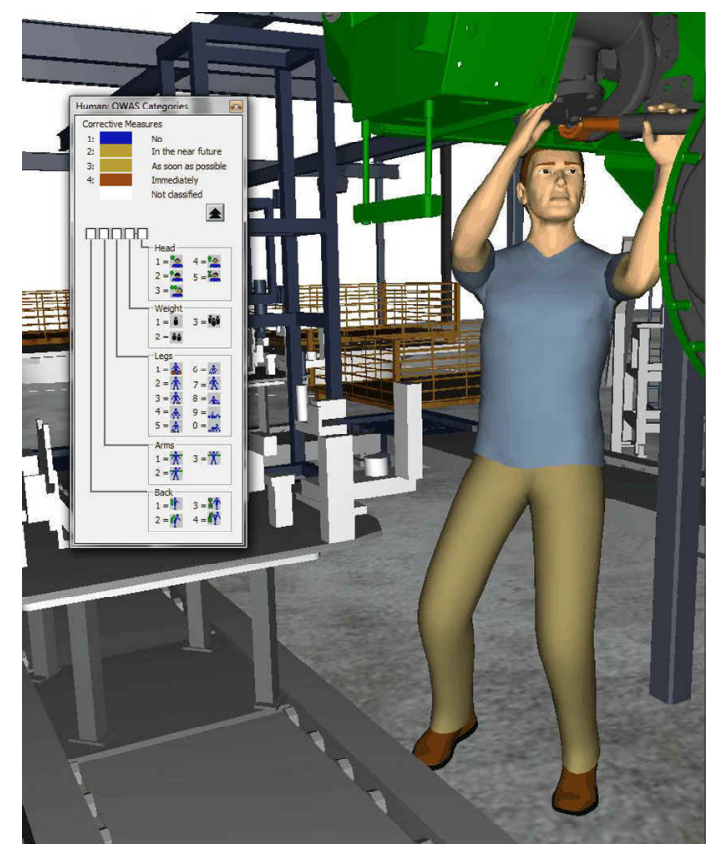

Fig. 3. Evaluation of overhead work using the OWAS method [3, p. 20; Software: 6]

Both methods provide an assessment of static work and indications of the need for redesign measures, albeit in different levels of detail. However, a dynamic assessment is not carried out as static work is only analysed at a specific point in time that is known to the user to be critical.

The static methods include the NIOSH load capacity method from the US and the RULA method from the UK. Based on the evaluation results, an assessment of the predicted stress on individual limbs is made using a traffic light assessment. The methods mentioned also take external forces into account, allowing both static posture and holding work to be evaluated.

It is apparent that Anglo-American evaluation methods dominate international human modelling procedures, while tools developed in Germany are typically not integrated into standard digital factory planning procedures. For example, the VDI method of determining load limits, which has been known in Germany for years, is 
available as a stand-alone computing procedure but not as a tool for the digital factory. It should be noted that the various methods for evaluation of static working in extreme cases can lead to different assessments of operations [7, pp. 114].

\subsection{Dynamic Analysis}

In the course of digital factory planning, dynamic aspects of human modelling are generally represented by taking into account the frequency or duration of movements under the influence of external forces and torques. The maximum possible forces and torques are reduced by reduction factors such as gender, age, training and frequency of movement. This principle is followed by the Guidance Characteristic Method, for example, for lifting and carrying, pushing and pulling, as well as repetitive manual work operations.

In other applications, the metabolic energy consumption is calculated based on systems of predefined loads. These kinds of approaches date back already to the 1920s. They can be combined with a system of predetermined times, and presented in table form. For example, the calculation of the metabolic energy consumption in accordance with Spitzer, Hettinger and Kaminski is included in the EKIDES procedure. However, this method is not a part of digital factory procedures used in Germany. At least the American human models JACK and JILL also include a prospective evaluation of human fatigue and recovery according to the formulae developed by Rohmert.

On the other hand, methods for calculating the dynamic stresses on human subjects to the influence of forces and accelerations are a largely undeveloped field with regard to digital factory planning. Military applications have been known already since the mid-1980s, especially with regard to aircraft piloting, which have been further developed for crash investigations in the field of automotive development. Another field of application can be found in sports science, for example the procedures being developed in Germany by Chemnitz University of Technology.

Other aspects of human modelling have been developed in Germany by the Karlsruhe Institute of Technology alongside the development of humanoid robots: If one hopes to make the movements of robots as humanlike as possible it is necessary to analyse human motions. Not only does this involve analysing the geometric properties and paths of motion of humans, but also the mass of their limbs and their inertia properties. The aim is then to synthesize motion paths, i.e. generating movements in accordance with the principles of forward dynamics or also inverse dynamics (analogous to forward kinematics and inverse kinematics). However, the principles according to which the motion paths should be generated, such as the principle of minimum torque, are yet largely unclear. These approaches therefore still require validation in comparison to real motion paths.

However, dynamic applications from the field of factory planning are not currently known. For example, while it is conceivable that the stress on the spine when walking on a floor with suspension properties could be evaluated, this has not yet been tested, and certainly not integrated into the digital factory procedures. Comparable applications are well known from the design of automobile seats and merely require 
transferring in order to be able to evaluate work stresses or even work aids provided by the suspension properties of a work platform.

Anatomical human models that take muscles, sinews and tendons into account in addition to limbs and joints show the way in this regard. The work of MIRALab at the University of Geneva in Switzerland deserves a particular mention in this regard. Figure 4 shows an example of the Danish human model AnyBody when getting in and getting out of a passenger car. The aggregated muscle activity is shown as a function of the handle height.
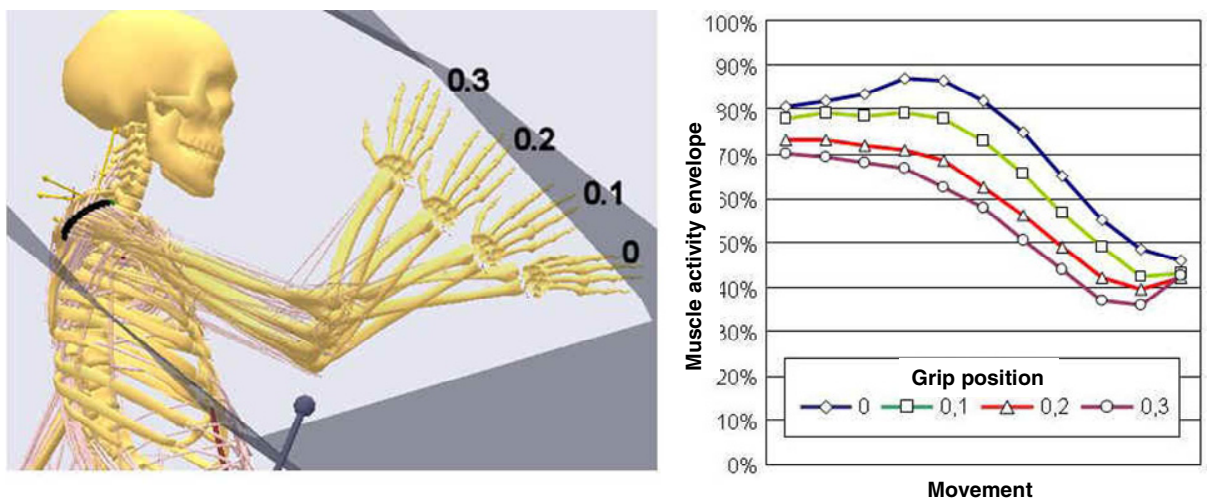

Fig. 4. Aggregated muscle activity during entry and exit from a car [3, p. 22; Software: 8]

\section{$3 \quad$ Need for Further Development}

The discussion of digital human models by the current VDI Guideline Committee based on the various aspects of engineering mechanics not only revealed the extent to which ergonomic aspects are already incorporated into various tools of the digital factory, but also their limitations. While anthropometric design can be seen as covered as a matter of standard in a wide area, there are still a number of questions with regard to physiological work design. It is apparent that evaluation options from the German-speaking world are rare in commercial tools. It is also proving particularly disadvantageous in operating practice that evaluation methods developed for the same ergonomic aspects sometimes produce different assessments. There continue to be deficits regarding the analysis of collisions between model elements, both for rigid bodies and particularly for flexible objects and their deformation as a result of collisions.

The examples given here show that the modelling of humans in digital factory tools is still far from adequate for the purpose of conducting ergonomic evaluations and assessments at a comprehensive level of work systems that only exist in a virtual form. The risk-assessment of future work systems in the interest of prospective occupational health and safety also poses a number of methodical questions. These mainly pertain to the evaluation and assessment of successive load cycles for a single type of 
stress and for several types of stress working simultaneously, both issues requiring further fundamental ergonomic research.

Acknowledgement. In his role as coordinator of the work presented here in summary, the author would like to thank all the members of the VDI Guideline Committee and everybody, especially from software companies, who have contributed their support.

\section{References}

1. VDI 4499 Blatt 1:2008-02: Digitale Fabrik - Grundlagen; Digital factory - Fundamentals. Beuth, Berlin (2008)

2. Systemes, D. (ed.): Virtual Ergonomics Solutions. Fellbach: Dassault Systemes Deutschland (2009), http: / / www. 3ds.com/de/products / delmia/solutions / human-modeling/overview/\#vid1 (accessed December 30, 2009)

3. VDI 4499 Blatt 4, Entwurf:2012-04: Digitale Fabrik - Ergonomische Abbildung des Menschen in der Digitalen Fabrik; Digital Factory - Ergonomic representation of humans in the digital factory. Beuth, Berlin (2012)

4. VDI 3633 Blatt 6:2001-10: Simulation von Logistik-, Materialfluss- und Produktionssystemen Abbildung des Personals in Simulationsmodellen. Beuth, Berlin (2001)

5. Gröber, A.: Deutsche wachsen weiter - aber eher in die Breite. Die Welt (April 21, 2009), http://www. welt.de/wissenschaft/article3595128/

Deutsche-wachsen-weiter-aber-eher-in-die-Breite.html (accessed April 13, 2014)

6. Siemens PLM Software (ed.): Jack and Process Simulate Human, http://www.plm.automation.siemens.com/en_us/products / tecnomatix/assembly_planning/jack/index.shtml (accessed May 25, 2009)

7. Zülch, G.: Perspektiven der Menschmodellierung als Werkzeug der digitalen Fabrikplanung. In: Schenk, M. (ed.) Digital Engineering - Herausforderung für die Arbeits- und Betriebsorganisation, pp. 105-124. GITO, Berlin (2009)

8. AnyBody Technology (ed.): Occupational Health. Anybody Technology A/S, Aalborg (2011), http://www.anybodytech.com/index.php?id=166 (accessed April $13,2014)$ 